\title{
Sustentabilidade ambiental: desenvolvimento com decrescimento?
}

José Eustáquio Diniz Alves*

\section{Resumo}

0 crescimento econômico e populacional exponencial é um fenômeno recente na história da humanidade. Durante milênios, a humanidade conviveu com baixas taxas de crescimento demo-econômico. Porém, após a Revolução Industrial e Energética (utilização de combustíveis fósseis), ocorrida no final do Século XVIII, a humanidade expandiu as atividades antrópicas por todos os cantos do Planeta, com grande impacto negativo na sustentabilidade dos ecossistemas. 0 Antropoceno - época da dominação humana - representa um novo período da história da Terra em que o ser humano se tornou a causa da escalada global da mudança ambiental. 0 objetivo deste texto é debater a insustentabilidade do modelo atual e como fazer a transição para um modelo de decrescimento.

Palavras-chave: População, desenvolvimento, decrescimento e sustentabilidade ambiental

"Professor Titular da Escola Nacional de Ciências Estatísticas (ENCE/IBGE). Doutor em Demografia pelo CEDEPLAR/UFMG, pós-doutorado no Núcleo de Estudos de População - NEPO/UNICAMP. 


\section{Introdução}

0 capitalismo foi 0 sistema de produção histórico que mais gerou riqueza material em todos os tempos. Antes da Revolução Industrial e Energética, no final do Século XVIII, o ritmo de crescimento econômico e o volume de produção de bens e serviços era muito modesto. Mas 0 aprofundamento da divisão social do trabalho junto com a aplicação de tecnologias de produção em massa e 0 uso indiscriminado de combustíveis fósseis fez a economia ter um crescimento exponencial. Em pouco mais de dois Séculos, a humanidade teve um impacto maior sobre a biosfera do que nos 200 mil anos anteriores da história do homo sapiens.

Entre 0 ano 1 da Era Cristã e 0 ano de 1800, a economia mundial cresceu 5,8 vezes, porém 0 crescimento entre 1800 e 2011 foi de 90 vezes, segundo os dados de Angus Maddison. Em 1800 anos, o crescimento da renda per capita foi de apenas 1,3 vezes ou $30 \%$, passando para 13 vezes em 211 anos. Ou seja, em pouco mais de dois Séculos a renda per capita mundial cresceu 10 vezes mais do que nos 18 Séculos anteriores.

Mesmo considerando que há desigualdade na distribuição da renda e na apropriação da riqueza, o volume geral de consumo aumentou muito e se difundiu por todas as camadas sociais (embora ainda existam em torno de $15 \%$ de pessoas na pobreza extrema no globo). 0 PIB mundial está acima de 70 trilhões de dólares e a renda per capita média mundial encontra-se acima de 10 mil dólares, segundo 0 FMI. A classe média global (familias com renda per capita de 10 dólares ao dia) já se aproxima de 3 bilhões de habitantes (segundo o PNUD), sendo três vezes maior do que toda a população mundial antes do início do capitalismo. É claro que muitos ganhos no padrão de vida médio da humanidade ocorreram devido aos avanços do processo civilizatório.

Contudo, 0 capitalismo busca incessantemente se apropriar de todos os meios e recursos possíveis, buscando maximizar os seus lucros. Mas com grandes danos ambientais. Ou seja, o capitalismo é um sistema antropocêntrico e que contraria os direitos ecocêntricos do Planeta.

\section{População e desenvolvimento: do antropocentrismo ao mundo ecocêntrico}

0 antropocentrismo é uma concepção que coloca o ser humano no centro das atenções e as pessoas como as únicas detentoras plenas de direito. Poderia parecer uma manifestação natural, mas, evidentemente, é uma construção cultural que 
separa artificialmente 0 ser humano da natureza e opõe a humanidade às demais espécies do Planeta. 0 ser humano se tornou a medida autorreferente para todas as coisas.

A demografia, assim como a economia e as demais ciências humanas, foi fortemente marcada pelo antropocentrismo, desde suas origens. Aliás, 0 antropocentrismo tem suas raízes mais profundas em antigos registros religiosos. 0 livro do Gênesis, do Velho Testamento, descreve que Deus criou o mundo em sete dias, sendo que no sexto dia, no cume da criação e antes do descanso do sétimo dia, Ele criou 0 ser humano (primeiro o homem e depois a mulher) à sua própria imagem e semelhança, ordenando: "Frutificai, multiplicai-vos, enchei a terra e sujeitai-a; dominai sobre os peixes do mar, sobre as aves do céu e sobre todos os animais que se arrastam sobre a terra". Esta concepção teo-antropocêntrica de superioridade e dominação humana reinou na mente das pessoas e nas diversas instituições durante milênios, especialmente no hemisfério Ocidental, e ainda está presente no mundo contemporâneo. Mesmo nos dias atuais, o "crescei e multiplicai-vos" orienta, por exemplo, as reações religiosas e conservadoras contra o processo de universalização dos métodos contraceptivos modernos.

Em reação ao mundo teocêntrico, o Empirismo e o lluminismo - movimentos que surgiram depois da Renascença - buscaram combater os preconceitos, as superstições e a ordem social do antigo regime. Em vez de uma natureza incontrolável e caótica, passaram a estudar suas leis e entender seu funcionamento. Associavam 0 ideal do conhecimento científico com as mudanças sociais e políticas que poderiam propiciar o progresso da humanidade e construir o "paraíso na terra". Os pensadores iluministas procuraram substituir o Deus onipresente e onipotente da religião e das superstições populares pela Deusa Razão. Em certo sentido, combateram 0 teocentrismo, mas não conseguiram superar o antropocentrismo, mantendo de forma artificial a oposição entre cultura e natureza, entre 0 cru e 0 cozido, a racionalidade e a irracionalidade.

Dois expoentes do lluminismo foram fundamentais para lançar as bases da demografia. No bojo da Revolução Francesa e no espírito da Declaração dos Direitos do Homem e do Cidadão (aprovada em 26/08/1789 pela Assembleia Constituinte), 0 marquês de Condorcet escreveu o livro Esquisse d'un tableau historique des progrès de l'esprit humain (1794) e William Godwin escreveu Enquiry concerning political justice, and its influence on general virtue and happiness (1793). Eles combateram o teocentrismo, mas não chegaram a questionar 0 antropocentrismo, pois estavam mais preocupados com o progresso material e cultural dos seres humanos, sem prestar a devida atenção aos direitos da natureza e das outras espécies.

Estes autores defendiam as ideias de justiça, progresso, mudanças nas relações sociais (inclusive nas relações de gênero) e perfectibilidade humana, de certa 
forma antecipando, teoricamente, o fenômeno da Transição Demográfica. Ambos acreditavam que os avanços da educação e da ciência e os progressos tecnológicos iriam reduzir a pobreza e as taxas de mortalidade e aumentar a esperança de vida da população. As mesmas forças racionais que ajudariam a diminuir as taxas de mortalidade também possibilitariam o decréscimo das taxas de natalidade. Como disse Condorcet: o perigo de uma superpopulação estaria afastado, pois os casais humanos não iriam racionalmente "sobrecarregar a terra com seres inúteis e infelizes". Godwin chegou a calcular a "capacidade de carga" do Planeta e era (assim com Adam Smith) muito otimista quanto aos efeitos positivos do crescimento populacional humano (eles não estavam muito preocupados com as outras espécies e com a biodiversidade).

Foi para rebater estas concepções progressistas (e no seio da reação conservadora à Revolução Francesa) que Thomas Malthus publicou o seu panfleto anônimo, de 1798: An essay on the principle of population, as it affects the future improvement of society with remarks on the speculations of Mr. Godwin, Mr. Condorcet, and other writers. Nota-se, pelo próprio título do ensaio, que Malthus não pode ser considerado o pioneiro da demografia moderna, pois ele estava apenas rebatendo as ideias, estas sim pioneiras, de Condorcet e Godwin. E Malthus rebateu da pior maneira possível.

0 princípio de população malthusiano - "A população, quando não controlada, cresce numa progressão geométrica, e os meios de subsistência numa progressão aritmética" - não tem base histórica e nem estatística. Para fundamentar a sua "lei", Malthus utilizou as taxas de crescimento da população dos Estados Unidos e as taxas de crescimento da produção de alimentos da Inglaterra. Este procedimento, elementarmente incorreto, não questionava os limites do Planeta e nem os direitos da biodiversidade, mas apenas dizia que, quaisquer que fossem os limites da natureza, o crescimento exponencial da população, mais cedo ou mais tarde, ultrapassaria a capacidade de produzir meios de subsistência. 0 objetivo era mostrar que o progresso do bem-estar humano e a redução da pobreza, objetivos básicos do iluminismo, seriam impossíveis diante da "miséria que permeia toda a lei da natureza". Portanto, Malthus defendia que 0 controle da população fosse realizado via aumento das taxas de mortalidade, o que ele chamava de "freios positivos", isto é, miséria, doenças e guerras. Se fosse hoje em dia, Malthus teria colocado as mudanças climáticas na sua lista de freios positivos e como um meio de aumentar a mortalidade dos pobres, pois o seu antropocentrismo era apenas para os ricos.

Em termos morais, para Malthus, a privação e a necessidade eram uma escola de virtude e os trabalhadores somente sujeitar-se-iam às péssimas condições de trabalho se estivessem premidos pela falta de meios de subsistência. Evidentemente, Malthus subestimou de forma deliberada os progressos tecnológicos e os avanços da Revolução Industrial, quando previu o aumento linear dos meios de subsistência. 
Em relação ao crescimento exponencial da população e às altas taxas de fecundidade, Malthus, enquanto pastor da Igreja Anglicana, simplesmente era contra os métodos contraceptivos e 0 aborto. Após ser criticado por William Godwin, Malthus introduziu, na segunda versão do ensaio (desta vez assinada), de 1803, a noção de "freios preventivos", isto é, restrições morais ao casamento precoce e adiamento da nupcialidade como forma de redução da parturição (a fecundidade marital continuaria natural, ou seja, sem a regulação humana). Malthus era contra o sexo e os filhos fora do casamento, sendo que a união conjugal (unicamente heterossexual) tinha função prioritariamente procriativa. Por tudo isso, Malthus rebateu as considerações de Condorcet e Godwin sobre os progressos da ciência e da tecnologia e sobre a redução das taxas de mortalidade e natalidade, para argumentar que 0 desenvolvimento humano seria impossível e que os trabalhadores deveriam receber apenas um salário de subsistência suficiente para manter 0 equilíbrio homeostático entre população e economia.

Evidentemente, Malthus virou alvo das críticas dos pensadores progressistas e socialistas. Por exemplo, Karl Marx considerava que a sociedade capitalista é capaz de produzir meios de subsistência em progressão ao bem maior do que 0 crescimento demográfico. Para ele, o "excesso" de população não é fruto de leis naturais como afirmava Malthus, mas sim um subproduto da lógica do capital, que continuamente gera mudança qualitativa de sua composição orgânica, com o permanente acréscimo de sua parte constante (meios de produção) à custa da parte variável (força de trabaIho). Este processo produz uma "superpopulação relativa" ou um "exército industrial de reserva", o qual regula a oferta e a demanda de trabalhadores de tal forma que, pela pressão dos desempregados sobre a massa de trabalhadores ocupados, o salário pode manter-se no nível de subsistência. 0 exército de reserva também proporciona a manutenção de um estoque humano à disposição do capital.

Para Marx, bastava resolver o conflito final da luta de classes a favor do proletariado e todos os problemas do mundo seriam resolvidos, podendo haver desenvolvimento irrestrito das forças produtivas, sem restrições da natureza. Contra a "lei de população" de Malthus, Marx formulou uma prototeoria relativista e não falseável: "Todo modo histórico de produção tem suas leis próprias de população, válidas dentro de limites históricos". 0 fato é que Marx não tinha teorias nem demográfica e nem ecológica. Além disso, o lema romântico utópico do comunismo - "De cada um, de acordo com suas habilidades, a cada um, de acordo com suas necessidades" é fortemente antropocêntrico, como se as necessidades humanas pudessem ser satisfeitas sem restrições aos direitos da Terra e das demais espécies. Engels chegou a escrever um livro glorificando o domínio humano sobre a natureza. Por conta disso, as correntes ecossocialistas atuais tentam corrigir, ainda sem grande sucesso, 0 evolucionismo produtivista e a instrumentalização da natureza, ideias embutidas nos 
fundamentos das teorias marxistas. Porém, não é uma tarefa simples substituir 0 vermelho (do socialismo) pelo verde (da ecologia).

Historicamente, a demografia nasceu e cresceu em torno do debate sobre população humana e desenvolvimento econômico. Este debate foi sintetizado no livro de Ansley Coale e Edgar Hoover Population growth and economic development in low-income countries, de 1958. A ideia apresentada no livro é a de que o processo do desenvolvimento econômico acontece de forma sincrônica com a transição demográfica, sendo que o desenvolvimento reduz as taxas de mortalidade e fecundidade e a transição demográfica altera a estrutura etária, diminuindo o ônus da dependência de crianças e jovens, o que favorece ao desenvolvimento. Porém, o livro alerta para a possibilidade de uma redução exógena das taxas de mortalidade nos países de baixa renda, sem uma queda das taxas de fecundidade e sem modificação endógena do processo de desenvolvimento econômico. Nestes casos, haveria uma situação de "armadilha da pobreza", pois existiria a possibilidade de ocorrer uma aceleração do crescimento populacional juntamente com um aumento do ônus da dependência demográfica de crianças e jovens, o que poderia impedir a decolagem (take off) do desenvolvimento.

Foi para resolver este problema que se avolumaram as recomendações neomalthusianas. Nota-se que, ao contrário de Malthus, os neomalthusianos propunham 0 freio da população por meio da limitação da fecundidade e não do aumento da mortalidade. Malthus achava que era impossível acabar com a pobreza. Os neomalthusianos acreditavam que seria possível acabar com a pobreza e avançar com 0 desenvolvimento econômico promovendo a transição da fecundidade. Este debate, típico das décadas de 1960 e 1970, esteve no centro das discussões da Conferência sobre População de Bucareste, em 1974. Os países ricos queriam promover o controle da natalidade, enquanto os países pobres queriam impulsionar o desenvolvimento. Venceram os segundos, com a seguinte palavra de ordem: " 0 desenvolvimento é 0 melhor contraceptivo". Diversos países (e os fundamentalismos religiosos) aproveitaram 0 argumento para combater ou relaxar as políticas de acesso aos métodos de regulação da fecundidade. A China promoveu o desenvolvimento econômico juntamente com o controle da natalidade mais draconiano da história (a política de filho único), todavia, o resultado aparece em uma enorme degradação ambiental. Portanto, em qualquer cenário, 0 grande vencedor tem sido 0 antropocentrismo, pois 0 desenvolvimento das forças produtivas e 0 aumento do bem-estar da humanidade têm ocorrido em detrimento da natureza e das outras espécies.

A Conferência de Meio Ambiente de Estocolmo, de 1972, já havia alertado sobre os limites do Planeta e a rápida degradação ambiental. Desde aquela época, já não era mais possível ignorar os danos ao meio ambiente. 0 resultado foi 0 surgimento do conceito de desenvolvimento sustentável, apresentado oficialmente 
pelo relatório Brundtland, de 1987: "0 desenvolvimento que satisfaz as necessidades presentes, sem comprometer a capacidade das gerações futuras de suprir suas próprias necessidades". Todavia, se o conceito de desenvolvimento sustentável foi um avanço no sentido de se preocupar com as futuras gerações humanas, não chegou a formular alternativas para a preservação das outras espécies e a conservação do Planeta. Por isto se diz que o desenvolvimento sustentável é um antropocentrismo intergeracional. Isto ficou claro quando a Cúpula do Rio (1992) aprovou a concepção antropogênica: "Os seres humanos estão no centro das preocupações para o desenvolvimento sustentável".

Desde a década de 1970, a ONU organiza conferências paralelas e desencontradas sobre "Meio ambiente" e "População e Desenvolvimento". Em uma ela diz defender a natureza e na outra ela diz defender o desenvolvimento. Na Conferência Internacional sobre População e Desenvolvimento (CIPD), realizada no Cairo, em 1994, foi dito que o desenvolvimento é um direito dos povos e todas as pessoas possuem direitos reprodutivos para decidir livremente sobre 0 tamanho da prole. Enquanto os pessimistas veem cada nova pessoa como mais uma "boca" (consumidor), os otimistas veem como mais um "braço" (produtor).

Embora essas ideias possam ser vistas sob diferentes óticas, não deixam de ser compatíveis com 0 pensamento de Ester Boserup e Julian Simon que viam 0 crescimento populacional como um indutor positivo do desenvolvimento econômico. Este último autor considera que quanto mais gente existir, melhor para o mundo, pois o que conta não são as bocas ou os braços, mas sim os cérebros (a inventividade humana). Embora poucas pessoas usem adequadamente os seus cérebros, Julian Simon serviu de inspiração para as políticas neoliberais do governo Ronald Reagan, sendo também um modelo teórico para os atuais céticos das mudanças climáticas, ou seja, daquelas pessoas que negam os problemas ambientais em nome do crescimento econômico e da continuidade da exploração dos combustíveis fósseis e da eterna dominação da natureza. Para estes positivistas e fundamentalistas de mercado, o aquecimento global ou não existe ou seria resolvido pela geoengenharia. Por tudo isto, Simon pode ser considerado o suprassumo do antropocentrismo, pois não leva em conta os impactos negativos das atividades humanas, inclusive 0 impacto negativo dos produtos de alguns dos cérebros mais "brilhantes" e das tecnologias mais sofisticas. Por estas e outras, a CIPD do Cairo nem tocou nos direitos reprodutivos das outras espécies e no direito de vida e reprodução da natureza. Não foram discutidas metas para a estabilização da economia e da população e o desenvolvimento continuou sendo visto como uma panaceia para resolver os problemas do mundo.

Porém, cresce a percepção de que não pode haver desenvolvimento sustentável por meio do contínuo crescimento da população e da economia. São cada vez maiores os riscos de se ignorar os limites ambientais do Planeta. Pela metodologia da 
Pegada Ecológica, as atividades antrópicas já ultrapassaram em $50 \%$ a capacidade de regeneração da Terra. 0 fato é que 0 incremento do consumo, de um lado, e 0 aumento da população, de outro, estão contribuindo, mesmo que de forma diferenciada, para uma rápida degradação ambiental. Não existe consumo sem população e nem população sem consumo. Crescimento econômico e populacional ilimitado é uma equação impossível em um Planeta finito.

A solução milagrosa do avanço tecnológico como forma de resolver os problemas do desenvolvimento e do meio ambiente também tem sido questionada, pois a maior eficiência microeconômica - produção de mais produtos com menos insumos - não significa menor demanda agregada. Ao contrário, o que tem acontecido nos últimos 200 anos é 0 aumento macroeconômico do consumo de energia e de recursos naturais à medida que cresce a eficiência produtiva. Isto é o que se chama de Paradoxo de Jevons, fenômeno observado pelo economista britânico William Jevons e que realça o fato de que, conforme as novas tecnologias conseguem elevar a eficiência de um dado recurso natural, seu uso total tende a aumentar ao invés de diminuir.

0 fetichismo da ciência e da tecnologia já havia sido questionado no início do Século XIX. Enquanto os iluministas e, posteriormente, os positivistas apostaram todas as suas fichas nos avanços científico e tecnológico para resolver os problemas da humanidade, os efeitos não antecipados da criatividade humana foram problematizados por ninguém menos do que Mary Shelley - filha de William Godwin e da feminista Mary Wollstonecraft -, que publicou, em 1818, o livro Frankenstein, the modern Prometheus. Na mitologia grega, Prometeu foi o herói que robou o fogo (a sabedoria) dos deuses para "iluminar" a humanidade e foi castigado por Zeus, que 0 amarrou a uma rocha enquanto uma águia comia o seu fígado dia após dia, durante a eternidade. No livro de Mary Shelley, Victor Frankenstein foi o médico (e químico) que desenvolveu uma tecnologia para dar vida a uma criatura, que ele mesmo renegou e que, involuntariamente, acabou causando grande infelicidade a todos ao seu redor. Na realidade, Frankenstein é uma metáfora sobre as consequências imprevistas dos avanços da ciência, da tecnologia e do desenvolvimento econômico. Um líbelo precoce contra a tendência de hipostasiar o progresso. 0 livro de Mary Shelley serve de alerta quanto aos perigos da racionalidade humana - característica que define 0 homo sapiens e 0 diferencia dos animais irracionais -, mostrando que a inteligência pode ser razão de sucesso ou de fracasso. Ou os dois ao mesmo tempo.

Foi também no Século XIX que o economista inglês John Stuart Mill publicou, em 1848, o livro Principles of political economy, em que questiona o impacto do crescimento populacional e econômico sobre o meio ambiente e defende 0 "Estado Estacionário", ou seja, o fim do crescimento econômico quantitativo e 0 estabelecimento de uma relação harmoniosa e qualitativa entre economia, população e meio 
ambiente. Stuart Mill deu um primeiro passo para a superação do antropocentrismo, ao deixar de engrossar 0 coro que vangloria 0 crescimento sem limites das forças produtivas. Hoje em dia, surge no debate não só a questão do Estado Estacionário, mas também a ideia do Decrescimento Econômico.

Todavia, mesmo após 220 anos, não existe consenso na comunidade internacional de como tratar as questões de população, desenvolvimento e ambiente. Os ricos culpam os pobres pelos problemas da miséria e da degradação ambiental e os pobres culpam os privilégios dos ricos pela pauperização das pessoas e da natureza. Os países desenvolvidos, em geral, tendem a buscar soluções para o desenvolvimento nos avanços tecnológicos. Alguns países em desenvolvimento ainda repetem frases do tipo: "Não existe problema populacional, mas sim população com problema", como se o impacto populacional fosse neutro e fosse possível resolver os problemas humanos apelando para uma exploração desregrada do meio ambiente. Por isto mesmo, no movimento ambientalista, a noção de crescimento econômico tem sido questionada e 0 conceito de desenvolvimento sustentável tem sido visto como um oximoro.

Em pleno Século XXI e às vésperas da Conferência Rio +20 , as posturas convencionais sobre a natureza ainda têm como base uma visão instrumental da utilização do conjunto de recursos ambientais disponíveis em função das pessoas. A modernidade avançou defendendo a ampliação dos direitos humanos, em suas diversas gerações: direitos políticos, civis, culturais, sociais, econômicos, direitos reprodutivos, etc. Mas a crise ecológica da modernidade decorre justamente da incapacidade de expandir estes direitos para outras espécies e para 0 Planeta. 0 atual modelo de desenvolvimento "marron" (poluidor), além de insustentável, pode fazer a humanidade caminhar rumo ao suicídio e ao ecocídio.

Segundo os dados de Angus Maddison, entre 1800 e 2011, a população mundial cresceu "aritmeticamente" sete vezes e a economia cresceu "geometricamente" cerca de 90 vezes, mostrando que o otimismo de Condorcet e Godwin estava mais próximo das tendências históricas do que o pessimismo de Malthus. Houve grande aumento da renda per capita mundial e a esperança de vida ao nascer passou de menos de 30 anos para cerca de 70 anos. Mas esta vitória humana teve como base a exploração de uma dádiva da natureza que forneceu imensas reservas de combustíveis fósseis para turbinar a economia. No processo produtivo, monstruosidades foram criadas, como imaginou Mary Shelley, em o Frankenstein (por exemplo, a bomba atômica). A produção de bens e serviços cresceu utilizando tecnologias (agro) tóxicas e queimando os recursos fósseis. Existem dúvidas quando será atingido o "Pico de Hubbert" (o início do declínio da produção da energia fóssil), mas o futuro pode não ser tão promissor quanto foi o passado, pois 0 custo acumulado da dívida com a natureza (o "pacto faustiano") deverá ser pago no Século XXI. 
Isto fica claro quando se observa que o aumento do padrão de consumo da humanidade deixou sinais de insustentabilidade ambiental por todos os lados: a erosão dos solos; desertificação de amplas áreas terrestres; desmatamento e aniquilamento de biomas; uso e abuso dos aquíferos; poluição e salinização das águas dos rios; e acidificação dos oceanos, com a consequente diminuição da fertilidade das fontes de vida. Mais da metade dos mangues e dos recifes de coral do mundo já foram destruídos. As atividades antrópicas trouxeram a maior extinção em massa da vida vegetal e animal da nossa história, com cerca de 30 mil espécies sendo extintas a cada ano. 0 ser humano mudou a química da terra e do céu, aumentando o dióxido de carbono na atmosfera e provocando 0 aquecimento global, com todas as consequências negativas deste processo sobre a biodiversidade.

Diante do aumento da probabilidade de colapso ecológico, nos últimos anos têm havido tentativas de incorporar os direitos ambientais - de terceira geração junto aos demais direitos humanos. Mas estes direitos ambientais giram em torno das pessoas e continuam tratando a natureza como objeto. A perspectiva antropocêntrica considera normal a mercantilização das espécies e da natureza, porém a Terra e os seres vivos deveriam possuir direitos intrínsecos, independentemente de suas utilidades para a população hegemônica. Cresce o movimento de advocacy em favor dos direitos dos seres sencientes e contra os maus tratos aos animais. As ciências humanas já abordaram, com maior ou menor profundidade, as discriminações provocadas pelo classismo, sexismo, escravismo, racismo, xenofobismo e homofobismo, mas pouco se falou do especismo, que é a discriminação existente com base nas desigualdades entre as espécies. Para tanto, 0 altruísmo ecológico deve substituir 0 egoísmo humano e a regulação dos "bens comuns" deve substituir a "tragédia dos comuns". A água, por exemplo, deve ser vista como um bem comum, mas não só da humanidade e sim de todas as manifestações de vida do Planeta. A água limpa e pura deve inclusive ter o direito de continuar sendo limpa e pura e não ser instrumentalizada por uma ou outra espécie.

Por tudo isto, a demografia não pode se preocupar apenas com 0 tamanho e 0 ritmo de crescimento da população humana. Também não basta conhecer as características de sexo e idade e a distribuição espacial das diversas subpopulações. Parafraseando Keynes, todo demógrafo vivo é escravo das ideias de algum demógrafo (ou economista) morto. Mas o grande desafio inovador da atualidade é romper com a perspectiva baseada em valores antropocêntricos e assumir uma mudança de paradigma, adotando uma postura voltada para os valores ecocêntricos (centralizados nos direitos da Terra, do conjunto das espécies e no respeito à biodiversidade). 0 ser humano não vive em um mundo à parte. Ao contrário, a humanidade ocupa cada vez mais espaço no Planeta e tem investido de maneira predatória contra todas as formas de vida ecossistêmicas da Terra. Darwin mostrou que as espécies vivas possuem um 
ancestral fóssil comum. Todas as espécies são parentes e vivem no mesmo lar. Não há justificativa para a dinâmica demográfica humana sufocar a dinâmica biológica e ecológica. A sustentabilidade deve estar baseada na convivência harmoniosa entre todos os seres vivos.

A Conferência das Nações Unidas sobre Desenvolvimento Sustentável, a Rio +20 , deveria enfrentar as ambiguidades do conceito de desenvolvimento sustentável, buscando abordar as questões demográficas e os direitos da Terra e dos animais, numa perspectiva ecológica e holística. Contudo, a preocupação com a Economia Verde não tem dado espaço para se pensar formas alternativas de organização social e de interação econômica que superem o modelo atual de produção e consumo. 0 colapso ecológico pode se tornar irreversível se a comunidade internacional não entrar em um acordo para reverter as tendências do aquecimento global e da depleção dos recursos naturais. 0 passo mais fundamental e necessário passa pelo rompimento com 0 antropocentrismo e a construção de um mundo mais justo e ecocêntrico.

\section{0 relativo sucesso econômico e 0 grande fracasso ambiental do capitalismo}

0 capitalismo é 0 sistema econômico que mais desenvolveu as forças produtivas da humanidade e mais estimulou 0 crescimento da economia e da população. Mas, ao mesmo tempo, se transformou no sistema com maior impacto negativo no meio ambiente e com maiores efeitos destrutivos sobre 0 capital natural do Planeta. Karl Marx e Friedrich Engels compreenderam claramente as novidades econômicas trazidas pelo capitalismo. No manifesto comunista, de 1848, demonstraram que "A burguesia desempenhou na história um papel eminentemente revolucionário".

Com o início da Revolução Industrial e Energética, liderada pelas forças do sistema capitalista - tendo como base de sustentação a propriedade privada, as livres forças do mercado e 0 apoio do Estado - houve um impressionante crescimento da população e da economia. A população mundial passou de 1 bilhão de habitantes em 1800 para 7 bilhões em 2011, um crescimento de sete vezes. No mesmo período, a economia internacional cresceu 90 vezes (segundo Angus Maddison). Isto quer dizer que houve um impressionante crescimento da renda per capita da população mundial. Ou seja, em 211 anos a renda per capita cresceu 13 vezes, enquanto nos 1800 anos anteriores tinha crescido apenas 1,3 vezes. 0 Gráfico 1 mostra que 0 crescimento econômico se descolou do crescimento populacional nos últimos 250 anos. 
Gráfico 1 Crescimento do PIB e da população no mundo: 1000 a 2030

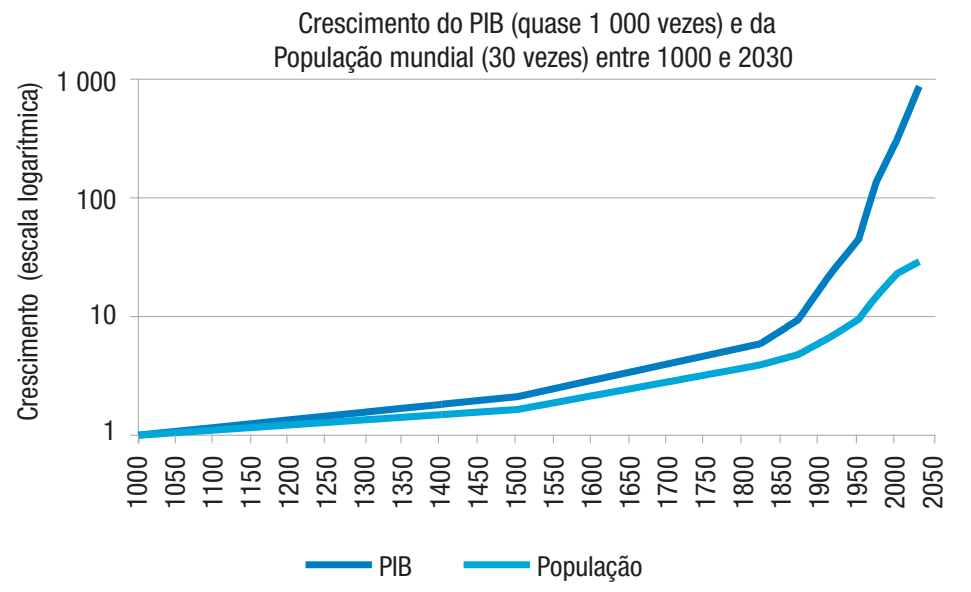

Fonte: Angus Maddison, Historical Statistics of the World Economy

Acompanhando 0 crescimento da renda, houve um grande aumento da esperança de vida ao nascer dos habitantes da Terra, que passou de menos de 30 anos em 1800 para quase 70 anos em 2011. Também houve um grande crescimento do consumo. Ao contrário do que previu Karl Marx, não houve um empobrecimento absoluto da maioria dos trabalhadores do globo. Como dizia Lenin, houve um crescimento da "aristocracia operária" nos países ocidentais. Depois da Segunda Guerra Mundial setores crescentes do proletariado avançaram na mobilidade social nos países da perifeira do sistema. Segundo o Programa das Nações Unidas para o Desenvolvimento (PNUD) houve redução da pobreza no mundo nos últimos 40 anos e a classe média global (pessoas com renda per capita acima de US\$10,00 ao dia) será maioria da população mundial até 2025 , pela primeira vez na história.

Isto representa um grande crescimento do consumo e uma grande exploração dos recursos naturais que sustentam a produção de bens e serviços, tais como: moradias, banheiro, água encanada, saneamento, produtos de limpeza e higiene, luz elétrica, geladeira, TV, DVD, CD, TV-HD, fogão, máquina de lavar roupa, móveis, micro-ondas, moto, bicicleta, carro, relógio, roupa, comida industrializada, telefone, celular, TV a cabo, Internet, educação, saúde, lazer, viagens, etc. Atualmente, existem mais de 1 bilhão de veículos automotores no mundo, número superior a toda a população do globo antes da Revolução Industrial. 0 número de celulares está caminhando para se igualar ao número de habitantes da Terra. 
Depois da queda do Muro de Berlim e do fim da União Soviética, o capitalismo se tornou uma força unipresente no mundo. Até países comunistas aderiram à onda consumista do capitalismo e assumiram a linha de frente da produção em massa e passaram a sustentar a dinâmica da economia internacional. Recentemente, o marxista Slavoj Žižek, em entrevista à Carta Maior, disse de forma irônica: "Só a China pode salvar o capitalismo".

Mas parece que não existe força visível capaz de salvar o meio ambiente da destruição capitalista. A degradação ambiental tem crescido de forma exponencial. 0 progresso da humanidade aconteceu às custas da regressão do capital natural. $A$ China é mais um exemplo de como o sucesso econômico leva ao regresso ambiental. As agressões à natureza tomaram uma dimensão crítica, profunda e global.

As áreas de florestas estão diminuindo para atender à demanda de madeira e à demanda de espaço para a agricultura e à pecuária. Espécies invasoras substituem a vegetação original. 0 mal uso do solo provoca erosão, salinização e desertificação. A poluição dos rios diminui a disponibilidade de água doce e provoca a mortandade de peixes. Lagos, como o mar da Aral, estão diminuindo ou secando para atender aos interesses da irrigação. A contaminação química e os agrotóxicos matam indiscriminadamente a vida terrestre e aquática. Aquíferos fósseis estão desaparecendo e os aquíferos renováveis não estão conseguindo manter os níveis de reposição dos estoques. A vida nos oceanos está ameaçada pelo processo de acidificação. 0s mangues e corais estão sendo destruídos a uma taxa alarmante. Aumentam as taxas de perda da biodiversidade (medida da diversidade de organismos vivos presentes em diferentes ecossistemas), com 0 aumento da degradação dos ecossistemas e a extinção da vida selvagem. 0 aumento das emissões de gases de efeito estufa está provocando 0 aquecimento global, tendo como consequência o derretimento das geleiras e das camadas de gelo, provocando escassez de água potável e 0 aumento do nível dos oceanos. As áreas produtivas da Terra diminuem, enquanto crescem os aterros para receber 0 crescente volume de lixo e resíduos sólidos.

0 relatório da UNEP da ONU "Global Environment Outlook-5: Environment for the future we want” (GE0-5) fornece um quadro dramático da degradação ambiental no mundo. Se a situação atual já está ruim, ela deve piorar devido ao crescimento populacional, à urbanização descontrolada, aos crescentes volumes de consumo e de lixo. Das 90 metas ambientais mais importantes, apenas quatro estão fazendo progressos significativos. Entre as metas que apresentaram melhoras, estão aquelas para evitar a destruição do ozônio e proporcionar 0 acesso a abastecimento de água limpa. Mas o documento relatou pouco ou nenhum progresso em 24 metas, tais como mudança climática, esgotamento dos recursos pesqueiros e a expansão da desertificação.

Tudo isso indica que o capitalismo e a defesa do meio ambiente funcionam por meio de lógicas diferentes e contraditórias. A lei máxima do capitalismo é a 
competição ou concorrência. As palavras-chaves são: explorar; dominar; padronizar; maximizar; crescer; produzir; utilizar; consumir; avançar; desenvolver; etc. Já a lei máxima da preservação da natureza é cooperar e as palavras-chaves são: proteger, conservar, minimizar os danos, recuperar, vivificar, reintegrar, diversificar, respeitar, manter fora do ciclo econômico, etc.

0 capital busca maximizar os lucros investindo em maquinarias, em inovações tecnológicas, em lançamento de novos produtos, em design, em conquista de novos mercados, etc. 0 s grandes capitalistas são aqueles que produzem a baixo preço e em grande quantidade. 0 ganho por unidade é pequeno, mas a receita total é grande (0 partido comunista chinês aprendeu bem esta lição de Adam Smith sobre os ganhos de eficiência da divisão social do trabalho).

Os trabalhadores - organizados em sindicados, associações e partidos - buscam maximizar seus salários, manter os direitos adquiridos e conquistar novos direitos e maior influência nas decisões nacionais. Desta forma, a lógica dos trabalhadores é atuar no sentido de elevar o seu padrão de vida, aumentando a sua participação no conjunto das riquezas geradas pelo capitalismo.

A lógica do Estado é aumentar suas receitas (geralmente impostos e taxas), expandir suas atividades e promover a grandeza e a segurança nacional. Algumas teorias dizem que 0 Estado é "o comitê executivo da classe dominante". Outras teorias dizem que 0 Estado é o mediador de conflitos entre 0 capital e trabalho e entre estes dois e 0 meio ambiente. Há ainda aquelas teorias que dizem que o papel do Estado é mais institucional no sentido de cuidar das fronteiras, evitar danos ao patrimônio nacional, realizar políticas públicas para 0 desenvolvimento econômico e humano, garantir a estabilidade política e jurídica e defender os interesses nacionais (dos cidadãos e empresas) em qualquer parte do mundo.

0 fato é que os capitalistas (industriais, comerciais, agrários, financeiros, etc.), os trabalhadores do campo e da cidade e a burocracia estatal - a despeito das divergências localizadas - tendem a se unir quando 0 assunto é crescimento econômico e a grandeza da Nação. Os chamados "projetos nacionais" são um conjunto de ações que unem os interesses deste conjunto de forças para garantir uma expansão do consumo e um aumento do padrão de vida da população nacional.

Nestes projetos, o meio ambiente é partido e repartido e se torna apenas um meio para se atingir os fins dos agentes econômicos. É claro que os mais inteligentes buscam conciliar 0 desenvolvimento econômico com a sustentabilidade ambiental. Ou seja, buscam garantir que a exploração e a dominação do meio ambiente continuem a acontecer no longo prazo e não sejam um entrave ao projeto de grandeza nacional e de conquistas econômicas do capital, do trabalho e do Estado. 0 desenvolvimento sustentável é a palavra de ordem daqueles que querem um capitalismo com colorido ou maquiagem "verde". 
Porém a lógica que prevalece no mundo é aquela que desconsidera que 0 crescimento populacional e econômico infinito é impraticável em um Planeta finito. A soma das ambições nacionais é muito maior do que 0 conjunto das reservas naturais do Planeta. Desta forma, os projetos nacionais estão entrando em choque com as condições ambientais em praticamente todos os países do globo. As disputas entre as classes, as nações, as religiões e as culturas já provocaram enormes danos ao meio ambiente, nestes últimos 200 anos. Nas atuais condiçoes de produção, para manter o bem-estar da população mundial (ou da maior parte dela), quem sai perdendo é o meio ambiente. As atividades antrópicas do capitalismo já ultrapassaram a capacidade de regeneração da Terra.

Enquanto 0 capitalismo cultua 0 enriquecimento, o meio ambiente, no geral, empobrece. As tentativas de conciliar a lógica do crescimento econômico com a lógica da cooperação ambiental são bem-vindas. Mas crescem as evidências de que, no conjunto, estas duas lógicas são inconciliáveis e estão entrando em rota final de colisão.

Ao invés das leis garantindo prioritariamente os direitos de propriedade, 0 pagamento do lucro e dos juros do capital financeiro é preciso criar uma legislação contra 0 ecocídio e contra os danos e a destruição em massa dos ecossistemas. Para alcançar o verdadeiro desenvolvimento sustentável, é preciso garantir de forma explícita que o direito à vida não é privilégio da espécie humana. Assim, é preciso tornar o Ecocídio um crime contra a natureza e um crime contra as gerações futuras.

A humanidade já avançou na abolição da escravatura, no fim do apartheid e na condenação do genocídio. Falta mudar a lógica de dominação da natureza. 0 ecossistema deve estar no centro das preocupações e da legislação internacional, no sentido de proteger a vida e a biodiversidade. A natureza tem valor intrínseco e não um valor instrumental como sugere a racionalidade capitalista. Hoje em dia, mais importante do que a luta de classe pela apropriação do excedente é a luta em defesa do meio ambiente, pela sobrevivência das espécies e pela erradicação do ecocídio.

Assim, podemos dizer que 0 capitalismo foi 0 sistema de produção histórico que mais gerou riqueza material em todos os tempos. Mesmo considerando que há desigualdade na distribuição da renda e na apropriação da riqueza, o volume geral de consumo aumentou muito e se difundiu por todas as camadas sociais (embora ainda existam em torno de $15 \%$ de pessoas na pobreza extrema no globo). 0 PIB mundial está acima de 70 trilhões de dólares e a renda per capita média mundial encontra-se acima de 10 mil dólares, segundo o FMl. A classe média global (familias com renda per capita de 10 dólares ao dia) já se aproxima de 3 bilhões de habitantes (segundo o PNUD), sendo três vezes maior do que toda a população mundial antes do início do capitalismo. É claro que muitos ganhos no padrão de vida médio da humanidade ocorreram devido aos avanços do processo civilizatório. Mas o capitalismo busca 
incessantemente se apropriar de todos os meios possíveis, buscando maximizar os seus lucros. Mas com grandes danos ambientais.

Parece que Karl Marx superestimou a oposição entre capital e trabalho (capital variável) como a maior contradição do capitalismo. Ele achava que a oposição entre capitalistas e proletários chegaria a níveis insustentáveis, o que levaria ao fim do capitalismo. Porém, o capitalismo tem conseguido se reorganizar de várias formas, expandindo as classes consumidoras.

Nas sociedades desenvolvidas - do capitalismo liberal (tanto no caso de menor presença do Estado, como nos Estados Unidos ou com maior presença estatal no sistema de proteção social europeu) - a burguesia conseguiu uma convivência institucional com o proletáriado em nome do crescimento do bem-estar geral da sociedade humana. Capital e trabalho convivem no desfrute da propriedade privada e na defesa da livre iniciativa, para elevar os níveis de consumo.

Na sociedade "socialista" - que na prática é uma espécie de "capitalismo de Estado", com a propriedade estatal substituindo a propriedade privada - a tecnoburocracia, a elite política e os trabalhadores se unem para fazer crescer 0 excedente econômico que é distribuido com a intermediação das forças do aparato público. A União Soviética foi um capitalismo de Estado que faliu quando Mikhail Gorbachev tentou fazer uma abertura política para enfrentar a crise do sistema soviético. Já a China é um capitalismo de Estado que manteve a centralização política de forma autoritária nas mãos do partido comunista, mas possibilitou uma grande abertura econômica que agradou as empresas públicas, as empresas privadas (nacionais e multinacionais) e os trabalhadores.

Tanto no capitalismo liberal, quanto no capitalismo de Estado, o capital e 0 trabalho se unem para aumentar a produção e a dominação da natureza. Embora existam conflitos e disputas pela distribuição dos excedentes (ou seja, da riqueza material), os diversos agentes sociais se unem na hora de aumentar a produção de alimentos, a extração de petróleo, a ampliação da mineração e a onipresente produção de bens e serviços para o deleite humano.

0 sociólogo francês Raimundo Aron dizia que capitalismo e socialismo tinham em comum a administração da sociedade industrial. Ou seja, uma mesma base produtiva baseada no uso dos combustíveis fósseis e na aplicação de tecnologias. Não é sem surpresa que a China se tornou o País com maior impacto negativo no meio ambiente.

Neste ponto, parece que Marx subestimou os problemas ambientais e tinha uma visão cornucopiana da natureza. Ele achava que no comunismo, com o avanço das forças produtivas, as pessoas poderiam caçar de manhã, pescar a tarde e fazer poesia à noite. Porém, Marx não chegou a defender 0 direito dos animais, não combateu o especismo e não fez uma defesa da biodiversidade. 0 marxismo foi conivente com a ideia de "domesticação" da natureza e não chegou a questionar o processo 
de dominação e exploração da vida natural. Na verdade, o ser humano em geral por meio do conjunto das atividades antrópicas - tem vilipendiado 0 capital natural oferecido de forma gratuita pela natureza.

Desta forma, mesmo soando herético, a burguesia e o proletariado (o primeiro com menos gente e mais consumo per capita e o segundo com mais gente e menos consumo per capita) formam um "capital antrópico" que estende e expande os seus tentáculos para a exploração do meio ambiente.

Mas o grau de poluição e degradação da natureza chegou a níveis tão elevados que a contradição entre o "capital antrópico" e o "capital natural" se transformou no grande conflito da sociedade capitalista (na sua forma liberal ou estatista/socialista) contemporânea.

Assim, 0 capitalismo (em todas as suas formas) está cavando 0 seu próprio fim. Mas não pela contradição interna entre burguesia e proletariado, mas sim pelo antagonismo entre 0 capital antrópico (que só aumenta a pegada ecológica da humanidade e reduz a biocapacidade e a biodiversidade da Terra) e 0 capital natural. Não será surpresa se a depleção da natureza colocar um fim (ou limitar bastante) as atividades antrópicas dos capitalismos em futuro não muito distante.

\section{Curva Ambiental de Kuznets: mais desenvolvimento é a solução?}

Diante do exposto, fica claro que o desenvolvimento econômico tem provocado progresso humano, mas regresso ambiental. Porém, alguns autores consideram que a solução para o mundo é avançar com mais desenvolvimento, pois os efeitos negativos teriam um ponto de inflexão, como sugere a Curva Ambiental de Kuznets (CAK).

Simon Kuznets (1901-1985) foi um economista nascido na Ucrânia, ganhador do Prêmio Nobel de 1971, que fez importantes contribuições aos estudos macroeconômicos. Originalmente, a "Curva de Kuznets" foi uma representação gráfica elaborada para expressar a hipótese de que 0 aumento da desigualdade de renda é uma tendência natural dos primeiros ciclos do desenvolvimento, mas que se reverte com o passar do tempo, pois as próprias forças de mercado se encarregariam de reduzir as desigualdades a partir do momento em que uma nação alcança certo limiar de renda per capita.

A Curva Ambiental de Kuznets (CAK) tem a mesma forma do "U invertido", mas é aplicada para a área ambiental. A CAK tem sido usada pelas pessoas que defendem 0 desenvolvimento econômico como uma prioridade em relação ao meio ambiente. A ideia básica é que o desenvolvimento só causa grandes problemas ambientais em suas etapas iniciais (no take off rostowniano). Porém, a partir de um certo ponto, 0 aumento 
Figura 1 A Curva Ambiental de Kuznets

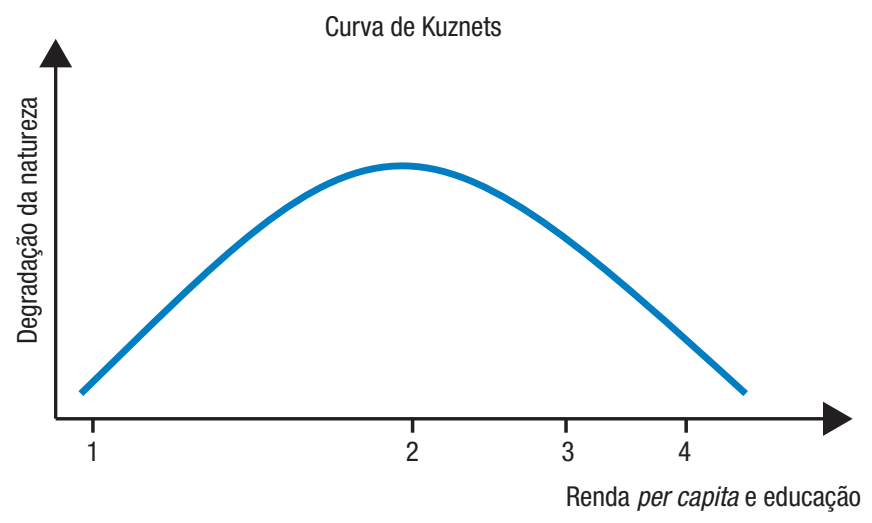

da renda per capita e da educação levaria a uma menor degradação ambiental. Portanto, segundo o otimismo kuznetiano, altas doses de desenvolvimento seriam úteis não só para reduzir as desigualdades sociais, mas também para salvar a natureza.

0 "U invertido" seria o melhor dos mundos se fosse verdade, pois investimentos em tecnologia e educação resolveriam os problemas simultâneos da pobreza e do meio ambiente. Mas a CAK é uma metodologia que ainda não foi comprovada, embora caia como uma luva ideológica perfeita, tanto para as diversas correntes nacionalistas (à direita e à esquerda) quanto para os economicistas, os positivitas, os socialistas stalinistas, os fundamentalistas de mercado, os neoliberais e os chamados céticos do clima.

Os dados dos Estados Unidos da América (EUA), em relação à desigualdade de renda, são ilustrativos. 0 índice de Gini diminuiu ligeiramente entre os anos de 1920 e 1970, podendo sugerir alguma praticidade da "Curva de kuznets". Porém, depois das políticas implantadas por Ronald Reagan e George Bush (pai e filho) a concentração de renda voltou a aumentar, apontando para um formato não de "U invertido", mas sim um formato "N", ou seja, um aumento inicial, depois uma queda, seguida de uma nova subida. Um estudo de 2011, feito pelo Congressional Budget Office (CBO), mostrou que os ganhos nominais da parcela dos $1 \%$ mais ricos da população norte-americana cresceu $275 \%$ entre 1979 e 2007 , contra $40 \%$ de aumento nominal dos $60 \%$ da base da pirâmide de renda.

Portanto, a "Curva de Kuznets" não se aplica para o caso dos EUA - País super-desenvolvido e líder da economia mundial. Por outro lado, países como Taiwan, Coreia do Sul e Singapura apresentaram rápido desenvolvimento econômico sem passar pela fase de grande concentração de renda. Desta forma, a CAK não acontece 
necessariamente nem na sua fase ascendente e nem na descendente. 0 professor José Gabriel Palma (2011), da Universidade de Cambridge, publicou artigo recente mostrando que não há prova alguma da veracidade da "Curva de Kuznets" em relação à desigualdade de renda, nos diversos países do mundo.

Quanto à curva ambiental, a questão é ainda mais complexa e a metodologia mais frágil. Na adaptação para o meio ambiente, a Curva Ambiental de Kuznets (CAK) representa a relação entre 0 aumento da renda per capita (e da educação) e a redução da degradação ambiental. Mas, Simon Kuznets não chegou a ver 0 uso e 0 abuso de sua curva. 0 início do uso da CAK é atribuido a um paper de 1991 de autoria dos economistas americanos Gene Grossman e Alan Krueger. Eles utilizaram medidas de poluição em cidades de 42 países e examinaram, por meio de técnicas econométricas, a relação entre qualidade do ar e crescimento econômico. Encontraram a forma do "U invertido" nos casos do dióxido de enxofre (S02) e fumaça.

Os estudos econométricos sobre a CAK, de maneira geral, apontam que 0 pico da degradação ambiental tende a ocorrer quando a renda per capita fica entre US\$ 5 mil e US\$ 8 mil. Após este nível, o crescimento econômico, em vez de causar degradação, seria a solução para o meio ambiente. Artigo dos pesquisadores Nemat Shafik e Sushenjit Bandyopadhyay foi utilizado para fundamentar o World Development Report, do Banco Mundial, em 1992. Das dez medidas de qualidade ambiental usadas, quatro demonstraram comportamento na forma de $\mathrm{U}$ invertido - falta de água, falta de saneamento urbano, partículas suspensas e S02. Em plena época neoliberal, estes tipos de estudos reforçaram a ideologia da desregulamentação, sugerindo que 0 mercado faria os ajustes necessários para a inclusão social e a sustentabilidade ambiental, na medida em que houvesse crescimento da renda per capita e da educação.

Segundo Pardini (2008): "Além de ignorar o sistema, seja ele uma economia local, seja o comércio global, a ideia por trás da CAK descola-se da realidade por não assumir que existe feedback entre a degradação ambiental e a economia. A relação é vista como tendo apenas uma mão - mais crescimento leva a menos poluição - e não 0 seu contrário - mais poluição leva a menos crescimento. Ignora a possibilidade de os efeitos da degradação ambiental serem irreversíveis e, portanto, afetarem a possibilidade de geração de renda".

De fato a degração ambiental só tem se agravado no mundo nas últimas décadas, como mostram os dados do aquecimento global, da poluição dos rios, lagos e oceanos, a extinção de 30 mil espécies por ano, as áreas de florestas estão diminuindo para atender à demanda de madeira e à demanda de espaço para a agricultura e a pecuária. Espécies invasoras substituem a vegetação original. 0 mal uso do solo provoca erosão, salinização e desertificação, etc.

Neste quadro geral de degradação ambiental, querer ressuscitar a CAK é fechar os olhos para a realidade crua e nua. 0 pesquisador David Stern (2004), do 
Rensselaer Polytechnic Institute, em Nova York, revendo os estudos sobre a Curva Ambiental de Kuznets, chegou à conclusão que quando se leva em consideração os diagnósticos estatísticos, os testes de especificação e se usa técnicas apropriadas, percebe-se que a CAK não existe: "Parece que a maioria dos indicadores de degradação ambiental aumenta monotonicamente com a renda".

Segundo o relatório Planeta Vivo, da WWF, a pegada ecológica da humanidade passou de 7,2 bilhões de hectares globais (gha), em 1961, para 17,3 bilhões de gha, em 2008, representando um consumo dos recursos naturais $50 \%$ acima da capacidade de regeneração do Planeta. A biocapacidade da Terra diminuiu de 3,2 hectares globais (gha) per capita, em 1961, para 1,8 gha per capita, em 2008.

Ou seja, tem havido diminuição da capacidade de produção biológica do globo, enquanto aumenta 0 consumo de bens duráveis e de alimentos provocado pelo crescimento populacional e econômico. Portanto, os últimos 200 anos da história do desenvolvimento econômico - desde a Revolução Industrial e 0 início do uso generalizado dos combustíveis fósseis - têm sido acompanhado pela degradação ambiental e, em geral, são exatamente os países mais ricos e mais educados que provocam 0 maior impacto negativo global. 


\section{À guisa de conclusões: planejando 0 decrescimento demo-econômico}

Pelo exposto, percebe-se que as atividades antrópicas já ultrapassaram os limites do Planeta. 0 ser humano, atualmente, vive às custas dos recursos naturais herdados do passado, seja quando queima os combustíveis fósseis, quando usa as madeiras e lenhas das florestas, quando se aproveita da biodiversidade, quando reduz os estoques de peixes, quando polui a riqueza natural dos rios, do ar e da terra, quando acidifica os oceanos ou quando suga e esvazia os aquíferos. 0 que a natureza construiu em milhões de anos, o homo sapiens está destruindo em décadas. Quando esta herança acabar, a relação entre passivo e ativo terá que se igualar e não haverá mais abundância de capital natural para se explorar.

0 desequilíbrio entre as atividades humanas e o meio ambiente só aumenta como mostra a metodologia da pegada ecológica (Global Footprint Network). A pegada ecológica serve para avaliar o impacto que 0 ser humano exerce sobre a biosfera. A biocapacidade avalia o montante de terra e água, biologicamente produtivo, para prover bens e serviços do ecossistema à demanda humana por consumo, sendo equivalente à capacidade regenerativa da natureza. Até meados da década de 1970 a humanidade ainda vivia dentro dos limites renováveis do Planeta. Mas, a partir daí, a pegada ecológica da população mundial foi crescendo continuamente na medida em que crescia o número de habitantes e a renda per capita, diminuindo a biocapacidade per capita.

Em 1961, a pegada ecológica per capita era de 2,4 hectares globais (gha) e a população mundial era de 3,1 bilhões de habitantes, sendo a biocapacidade per capita de 3,7 gha. Desta forma, a humanidade estava utilizando $63 \%$ da capacidade regenerativa da Terra, havendo sustentabilidade ambiental. Em 1975, a pegada ecológica e a biocapacidade per capita passaram, respectivamente, para 2,8 gha e 2,9 gha e a população mundial chegou a 4,1 bilhões de habitantes. A humanidade estava usando 97\% da capacidade de regeneração, ainda cabendo dentro de um Planeta. A partir desta data, as atividades antrópicas ultrapassaram os limites biológicos da Terra.

Em 2008 (último dado disponível), a pegada ecológica per capita mundial ficou em 2,7 gha e a biocapacidade em 1,8 gha, sendo que a população global chegou a 6,75 bilhões de habitantes. Portanto, a humanidade estava usando 1,5 planetas, ou seja, um planeta e meio em 2008. Nota-se que a pegada ecológica per capita não cresceu nas últimas três décadas, mas sim o número de habitantes do globo, o que provocou a redução da biocapacidade per capita.

As projeções do relatório Planeta Vivo, da WWF e da Global Footprint Network, indicam que a humanidade estará utilizando dois Planetas em 2030 (ano em que 
poderá haver 8,3 bilhões de habitantes). É claro que alguns países possuem pegadas ecológicas enormes e outros bem abaixo da média mundial. Assim como em outros indicadores, a pegada ecológica ocorre de maneira desigual e cresce diretamente com o nível de renda. Porém, mesmo que houvesse uma justa distribuição de renda no mundo, o nível de produção e consumo internacional já seria insustentável, pois as fronteiras planetárias foram ultrapassadas. A pegada ecológica média já ultrapassou os limites sustentáveis de um planeta, conforme mostra 0 Gráfico 2.

Todavia, a ideologia desenvolvimentista e a mistificação do crescimento econômico só agravam a situação. Ao invés de um PIB ascendente rumo ao infinito, o que a Terra precisa é de uma mobilização para reverter a pegada ecológica, interromper 0 aquecimento global, melhorar a biocapacidade, proteger a biodiversidade e evitar a depleção ambiental. 0 crescimento e a concentração exagerados estão criando deseconomias de escala e a antiga sinergia está se transformando em entropia.

Portanto, é preciso pensar o impensável, ou seja, pensar em decrescimento. Mas o decrescimento não pode ser imaginado apenas como um espelho invertido do crescimento. Seria traumático um decrescimento imediato e desorganizado. Isto equivaleria a gerar uma depressão, com a consequente explosão do desemprego.

0 decrescimento tem que ser planejado no longo prazo, pois, no curto e médio prazo, o que pode haver é decrescimento do ritmo de crescimento. países ricos já podem reduzir as taxas de crescimento, como já ocorre, por exemplo, com o Japão. Mas, países muito pobres ainda precisam crescer, especialmente porque possuem populações rejuvenescidas com altas taxas de dependência de jovens e elevado ritmo de aumento demográfico. Desta forma, alguns países precisam crescer, enquanto

Gráfico 2 Pegada ecológica, biocapacidade e população. Mundo: 1961 - 2008
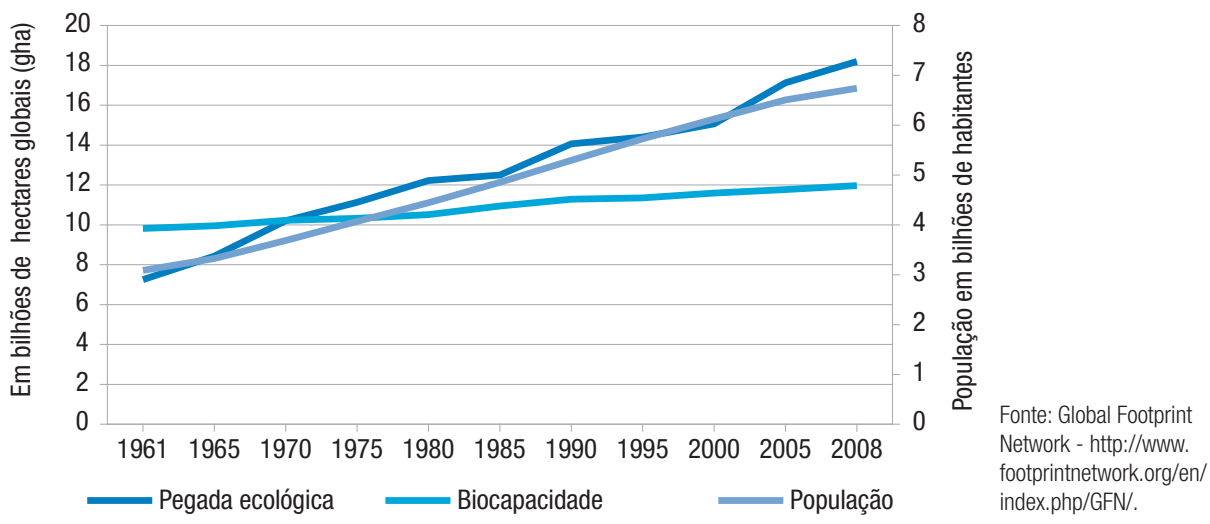
o mundo deve avançar na eliminação da pobreza e exclusão social, por meio da redução das desigualdades nacionais e internacionais de renda e patrimônio.

Do ponto de vista econômico, algumas atividades não devem nem crescer e nem decrescer, mas serem totalmente suprimidas (como as bombas atômicas, as guerras, o desmatamento, a matança de animais selvagens, etc.). Outras atividades devem diminuir, como a produção de carros particulares, a produção de combustíveis fósseis, a emissão de gases de efeito estufa, o consumo de carnes, o luxo, o lixo, etc. Já outras atividades precisam crescer, como a educação de qualidade, a saúde preventiva e desmedicalizada, a solidariedade interpessoal, etc.

Uma alternativa para se reduzir a pegada ecológica é diminuir o uso de combustíveis fósseis e aumentar 0 uso de fontes renováveis, como energia eólica, solar, geotérmica, das ondas, etc. Mas não basta apenas alterar a matriz energética, pois é preciso construir prédios sustentáveis, dar prioridade ao transporte coletivo, revolucionar a produção pecuária, com a captura de metano, incentivar a dieta vegetariana, fazer uma agricultura menos petroficada, com menos agrotóxicos e mais orgânica, apoiar a aquacultura, além de caminhar rumo a uma sociedade do conhecimento baseada em bens e serviços imateriais e intangíveis. A ideia do Estado Estacionário já havia sido bem colocada por John Stuart Mill, em meados do Século XIX, muito antes da humanidade ultrapassar as fronteiras planetárias.

Do ponto de vista demográfico, é preciso planejar o decrescimento, pois não basta diminuir 0 consumo médio. Cada pessoa tem um impacto inevitável sobre 0 meio ambiente, pois todo cidadão deseja possuir moradia, água potável, banheiro, saneamento e produtos de limpeza e higiene, luz elétrica, geladeira, televisão, DVD, $\mathrm{CD}$, fogão, máquina de lavar roupa, móveis, micro-ondas, moto, bicicleta, carro, relógio, roupa, comida industrializada, telefone, celular, TV a cabo, Internet, educação, saúde, lazer, viagens, etc. Ninguém vive de brisa.

Decrescer economicamente, mas manter 0 crescimento populacional poderia ser desastroso, pois poderia reduzir não só a renda per capita, mas a qualidade de vida em geral. 0 decrescimento populacional não deve ser encarado como 0 vetor principal do decrescimento das atividades antrópicas, porém como uma via auxiliar. Não existe população sem consumo e nem consumo sem população. Portanto, 0 decrescimento demográfico é uma maneira que se soma às iniciativas globais para se reduzir a pegada ecológica e aumentar a biocapacidade. Já existem muitos países com decrescimento populacional, como Rússia, Ucrânia, Japão, Cuba, etc. Todavia a população mundial, na média, ainda está crescendo cerca de $1 \%$ ao ano. Segundo projeções da $0 \mathrm{NU}$, existem três cenários até 0 fim deste século, qua variam de 6,7 a 16,6 bilhões de habitantes. 0 principal determinante da dinâmica demográfica mundial é a taxa de fecundidade, pois a esperança de vida global deve continuar sua saudável tendência de aumento lento, mas constante. 
A taxa de fecundidade mundial era de 5 filhos por mulher em 1950 e caiu para 2,5 filhos por mulher em 2010 e permanecendo constante nas próximas décadas resultaria em uma população de 16,6 bilhões em 2100, conforme mostra 0 Gráfico 3. Mas se a taxa de fecundidade cair para 2,1 filhos por mulher e permanecer constante, do nível de reposição da população, resultaria em uma população de 10,9 bilhões de pessoas em 2100. Contudo, se a taxa de fecundidade cair para 2,1 filhos por mulher até 2025 e continuar caindo até 1,7 filho por mulher até 2060 , então a população mundial atingiria um máximo de 8 bilhões de habitantes por volta de 2030 e depois cairia para algo em torno de 6,7 bilhões de habitantes em 2100. Uma população menor junto com uma mudança no padrão de produção e consumo ajudaria na diminuição dos impactos negativos da economia sobre os ecossistemas.

Reduzir imediatamente 0 crescimento populacional atual é praticamente impossível, devido à inércia demográfica. Mas no longo prazo é possível planejar 0 decrescimento populacional que viria reforçar a diminuição da pegada ecológica e 0 enfraquecimento da concentração de gases de efeito estufa na atmosfera. Atingir uma taxa de fecundidade de 1,7 filho por mulher (com políticas que respeite os direitos sexuais e reprodutivos) não é nada impossível. 0 Brasil, por exemplo, sem nenhuma política controlista, já possui uma taxa de 1,9 filho por mulher e deve chegar a 1,7 filho até 2020. Em Cuba a taxa de fecundidade é de 1,5 filho por mulher $\mathrm{e}$ na Alemanha de 1,3 filho. Na Coréia do Sul é de 1,2 filho e em Taiwan é de 1,0 filho por mulher.

Taxas de fecundidade abaixo do nível de reposição tendem a se generalizar no mundo, devido ao pico do petróleo, ao aumento do preço dos alimentos e à reversão

\section{Gráfico 3 População mundial de 1950 a 2010 e três cenários de} projeção até 2100

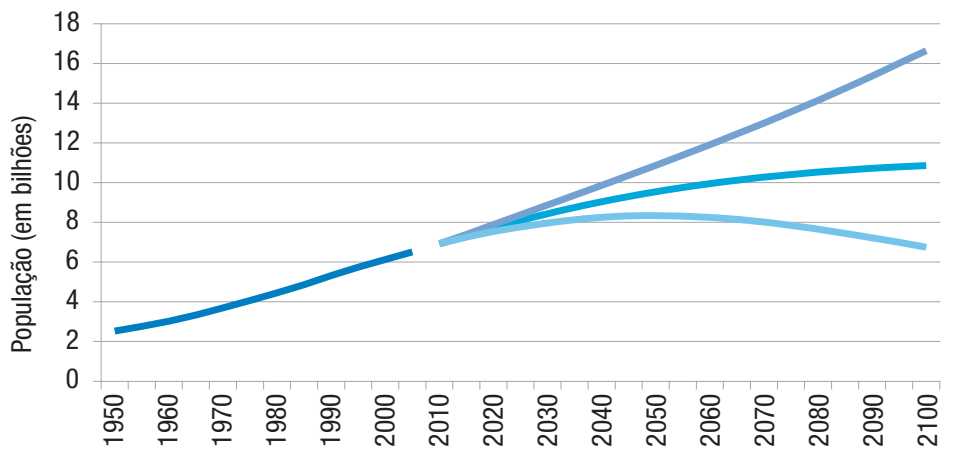


do fluxo intergeracional de riqueza, gerada pelas mudanças sociais e familiares. Se houver uma forte crise ambiental com fecundidade elevada, 0 ajuste pode ser feito pela via da mortalidade, 0 que não é desejável.

Muitos crimes já foram cometidos em nome do dístico: "Pátria e Poder". São os positivistas, os fundamentalistas religiosos e os fundamentalistas de mercado que consideram que as nações precisam de grandes populações com grandes economias para se impor na comunidade internacional. Porém, esta lógica desenvolvimentista é baseada na competição e não na cooperação. Para a saúde do planeta e 0 futuro da humanidade, 0 importante não é a quantidade, mas sim a qualidade. As ações são locais, mas a solucão deve ser global. Assim, não restam dúvidas que é possivel haver prosperidade com decrescimento demo-econômico. Numa perspectiva ecocêntrica, quanto menor for 0 impacto das atividades antrópicas, melhor. 


\section{Referências}

ALVES, J.E.D. Do antropocentrismo ao ecocentrismo: uma mudança de paradigma. In: MARTINE, George (Ed.) População e sustentabilidade na era das mudanças ambientais globais: contribuições para uma agenda brasileira. Belo Horizonte: ABEP, 2012.

Dave Lindorff. Growth is the Enemy of Humankind. 17/01/2013. Disponivel em: http://www.nationofchange.org/growth-enemy-humankind-1358432599.

GEORGESCU-ROEGEN, N. 0 decrescimento: Entropia, Ecologia, Economia. Editora SENAC, SP, 2013.

Global Footprint Network: http://www.footprintnetwork.org/en/index.php/GFN/.

FMI. World Economic Outlook: http://www.imf.org/external/datamapper/index.php

MADDISON, Angus. Historical Statistics of the World Economy. Disponível em: http://www.ggdc.net/maddison/oriindex.htm.

MARX, Karl; ENGELS, Friedrich. Manifesto comunista, 1848. Disponível em: http:// www.ebooksbrasil.org/eLibris/manifestocomunista.html.

PALMA, J. G. Homogeneous middles vs. heterogeneous tails, and the end of the 'Inverted-U': the share of the rich is what it's all about, Cambridge University, 2011. Disponível em: http://www.econ.cam.ac.uk/dae/repec/cam/pdf/cwpe1111.pdf.

PARDINI, Flávia. Por trás de uma curva. Página 22. São Paulo, 18/10/2008.

Disponível em: http://pagina22.com.br/index.php/2008/10/por-tras-de-uma-curva.

PNUD. Relatório de Desenvolvimento Humano 2013, PNUD, março de 2013. Disponível em: http://www.pnud.org.br/arquivos/rdh-2013.pdf.

STERN, David. The Rise and Fall of the Environmental Kuznets Curve. World Development Vol. 32, No. 8, pp. 1419-1439, 2004.: http://home.cerge-ei.cz/ richmanova/UPCES/Stern\%20-\%20The\%20Rise \%20and\%20Fall\%20of\%20 the\%20Environmental\%20Kuznets\%20Curve.pdf.

UN/ESA. World Population Prospects: The 2010 Revision, Disponível em: http://esa. un.org/unpd.

UNEP/ONU. Global Environment Outlook-5: Environment for the future we want" (GE0-5), 2012 http://www.unep.org/geo/pdfs/ge05/GE05_FrontMatter.pdf. 